\title{
TEMOS O DEVER DE MORRER?
}

\author{
Wendell Evangelista Soares Lopes*
}

\begin{abstract}
O texto se volta para questões éticas relativas à morte ou ao prolongamento da vida. Ao tentarmos oferecer uma resposta para o problema do prolongamento da vida ou do que se pode bem chamar de a nova busca científica pela imortalidade terrena, refletiremos sobre a atual querela entre mortalistas e imortalistas. Nosso ponto de partida é a aceitação de uma virtual imortalidade como algo realmente possível. O problema de um prolongamento meramente otimizador, isto é, de uma expectativa de vida de 150 anos para todos, levanta, a nosso ver, problemas por vezes distintos. Nesse sentido, pretendemos mostrar que, apesar do fardo da mortalidade, a condição mortal do ser humano possui um sentido moral claro, que exige de cada um o verdadeiro dever de morrer - em paradoxal relação com os já conhecidos direito à vida e direito de morrer.
\end{abstract}

Palavras-Chave: Ética. Vida. Morte. Direito.

\section{INTRODUÇÃO}

“Temos o dever de morrer?" - eis o título de nosso ensaio. Ele contém, em si mesmo, uma ambiguidade e uma provocação, pois se pode logo perguntar: é realmente necessário falar de um dever a respeito daquilo que é o mais fatal e não remediável, isto é, a morte? Ora, antes se podia dizer com o coro de Antígona: "sagaz e sem medo, [o homem] enfrenta o futuro. Só não consegue encontrar salvação contra o Hades, embora saiba curar males sem remédio". Mas tudo isso mudou. Sobre esse simples ponto já se pode perceber todo o valor da novidade tecnológica atual em relação à antiga téchne, pois até esse último dos "males sem remédio", o Hades, a moderna tecnologia, busca abater. No mínimo, temos de dizer que o "remédio" - ou pelo menos, sua fórmula - já tem sido buscado. Para que se perceba a gravidade do pro-

\footnotetext{
* Doutorando em Filosofia pela Universidade Federal de Minas Gerais. Bolsista CAPES.

Faculdade de Filosofia e Ciências Humanas. Av. Antônio Carlos, 6627, Cidade Universitária, $4^{\circ}$ andar, sala 4051. Cep: 31270-901. Belo Horizonte - Minas Gerais. wendelleslopes@hotmail.com
}

blema em que entramos com a alvorada do novo milênio, mantenhamos diante dos olhos essa metáfora do remédio. Todo "remédio" só o pode ser para uma "doença", que, por sua vez, precisa ser diagnosticada. É é sob essa perspectiva que a morte passa a ser enxergada com os atuais avanços técnico-científicos. Duas rotas para o diagnóstico se mostram sensíveis nesse particular: do lado da biologia, a morte passou a ser compreendida como mera disfunção de uma carcaça com defeito de fábrica, o corpo, cujo envelhecimento não é mais visto como um destino natural irreparável; por outro lado, com os avanços da cibernética, o corpo não é visto sequer como necessário, podendo ser tranquilamente eliminado. Como resposta a esse diagnóstico, o leque de possibilidades (fantasiosas e reais) dos "remédios" ou engenhos técnicos de reparação e abolição da doente e ultrapassada carcaça revestidora, isto é o combate contra o nosso corpo mortal, é enorme e engloba a criogenia, a ressurreição via clonagem, os transplantes de órgãos (incluindo o cérebro), as promessas da nanotecnologia, o uso de hormônios do crescimento humano, a pesquisa com interruptores genéti- 
cos que controlam o envelhecimento, a perspectiva dos ciborgues e bioputers, os processos de "mind uploading”, e até o teletransporte. É importante salientar também, nesse contexto, a existência de um já aquecido mercado de produtos antienvelhecimento (McConnel; Turner, 2005).

São esses possíveis meios de combater a "doença" que, de um modo ou de outro, direcionam e aguçam as expectativas dos desesperados ainda mortais quanto aos prognósticos da "doença" como tal. Certamente, não há consenso quanto a isso. Mas, para o que nos importa aqui, é sugestiva a distinção feita por Daniel Callahan (2002-2003, p.14): ele distingue os prognósticos em "normalização” (média de 85 anos para todos), "otimização" (expectativa de 120 anos para todos) e "maximização" (150 anos para cima, indefinidamente), o que bem poderíamos chamar de uma perspectiva de "virtual imortalidade”. Naturalmente, é fato que há ainda os céticos em relação a qualquer uma dessas perspectivas. Não obstante, há também muitas razões para se levar a sério os prospectos. Dentre elas, não se pode esquecer o que o trabalho dos biodemógrafos já nos relata: a expectativa de vida das pessoas aumenta consideravelmente a cada dia, e isso de maneira espontânea, sem que qualquer esforço direto para tal meta seja levado a cabo. $\mathrm{O}$ que dizer, então, dos resultados que poderão ser alcançados com as pesquisas diretamente direcionadas para esse fim? Mais ainda: face aos feitos cada vez mais estrondosos da tecnologia, nenhuma possibilidade deve ser descartada de antemão, e é preciso realmente escutar com atenção quando um "tecnoprofeta" como Aubrey de Grey (2009, p. 85) especula, por exemplo, que “a primeira pessoa a viver até 1000 anos já poderia estar com 60 anos”. Para além das especulações, não podemos fechar os olhos para questões de cunho judicial e legal que já emergem sobre a natureza jurídica do cadáver, como no caso da criogenia. ${ }^{1}$ Ademais, há de se considerar que esse

${ }^{1}$ No Brasil, por exemplo, o problema da imortalidade terrena alcançou uma ressonância que ultrapassa a simples esfera da discussão hipotética sobre o valor da imortalidade como tal. No ano passado (ano de 2012), a justiça brasileira conheceu um intrigante caso que coloca em questão tipo de biotecnologia imortalista é a que escancara, de forma mais radical, a questão do melhoramento e a alteração da imagem de homem que possuímos, e, nesse sentido, levanta irrecusavelmente questões éticas que merecem um tratamento mais detido.

Ao tentarmos oferecer uma resposta para o problema do prolongamento da vida ou do que se pode bem chamar de a nova busca científica pela imortalidade terrena, nos colocaremos entre o que hoje já é a querela entre mortalistas e imortalistas. Nosso ponto de partida é a aceitação de uma virtual imortalidade como algo realmente possível. $\mathrm{O}$ problema de um prolongamento meramente otimizador, isto é, de uma expectativa de vida de 150 para todos, levanta, a nosso ver, problemas por vezes distintos. Nesse sentido, a tese que defenderemos visa a demonstrar que, apesar do fardo da mortalidade, a condição mortal do ser humano possui um sentido moral claro, que exige de cada um o verdadeiro dever de morrer - em paradoxal relação com os já conhecidos direito à vida e direito de morrer.

Como primeiro ponto de nossa discussão, devemos confessar que a mortalidade é verdadeiramente um fardo a se carregar. Em nada nos alegra o fato de que, no futuro, nossa existência se extinguirá, e que, como amantes da vida, não poderemos mais desfrutar de tudo que em nossa vida temos apreço e amamos fazer. A mim, pessoalmente, nunca me satisfez, portanto, a famosa investida

a natureza jurídica do cadáver: sua conservação por meio da criogenia. O processo judicial tem se desenrolado de forma inédita na esteira da briga familiar - entre filhas, em específico - em torno da vontade de uma das partes a filha caçula Ligia Monteiro, que já gastou mais de 100 mil reais para a conservação do corpo em função da espera da decisão judicial - em conservar o corpo do pai, Luiz Felippe Dias de Andrade, em uma empresa americana de criogenia, e a vontade da outra parte - as outras duas filhas mais velhas - em velar e sepultar o corpo do pai morto. A questão jurídica é simples: a quem está reservado o direito sobre o cadáver do pai, uma vez que este, em vida, nada deixou por escrito a respeito de seu destino pós-quase-morte (já que a criogenia lhe promete um retorno à vida no futuro)? Mais: qual a legitimidade jurídica que garante a própria ação de uma empresa que promete uma possível ressurreição dos mortos? Ainda que porventura venha a estar habilitada para tal - algo que ainda não o está, mas que pode estar no futuro, o que a livra da charlatanice pura e simples -, permitindo-lhe legalmente atuar nesse sentido. Essa situação particular levanta para agora a discussão do problema da própria legitimidade da atuação de uma tal empresa, ou, pelo menos, das regulações cabíveis para a sua atuação. 
de Epicuro, ao tentar mostrar que o temor da morte é irracional. Para dizer o mínimo, esse componente químico do tetrapharmacon pressupõe já um-depois-da-morte: pois como poderia um cristão do período medieval - e mesmo alguns dos tempos de hoje - dizer que não há o que se temer quanto ao inferno - um lugar onde se alastra o ranger de dentes? Isso seria loucura! Para que não nos recaia a acusação de uma crença no inferno cristão, levantaremos outro exemplo pós-morte que certamente não é tão agradável como o que pressupõe Epicuro: refiro-nos àquele que retorna eternamente e que, como Nietzsche não deixou de anunciar a todos e a ninguém, exige de cada um, a cada segundo, decidir pelo melhor sob pena de um fardo eterno. Ademais, podemos dizer que, nos progressos constantes que a medicina vem realizando para estender a vida em detrimento da morte, é apenas expressão de um temor irracional? Não cremos. Antes, eles nos parecem ser expressão de um desejo humano, demasiado humano. Do ponto de vista filosófico propriamente, tudo fica ainda mais evidente quando, desde uma perspectiva existencial, Heidegger nos convidou a pensar o Dasein como ser-para-morte. Por causa da precisão heideggeriana, descobrimos que o temor da morte deve ser traduzido por angústia de morte. E dizer que angústia de morte é algo irracional é o mesmo que dizer que o homem não pode ser homem. De forma ainda mais radical, Jonas concebe o fardo da mortalidade como uma condição inerente a todo ser vivo - e, portanto, ao homem como vivente. A "mortalidade" é um fardo porque é a "possibilidade da morte que está sempre a espreitar toda a vida" (Jonas, 2009, p. 274). À audácia da vida se contrapõe o risco original da liberdade vital, a aparência da morte, diante da qual o preço que a vida paga é a constante e agonizante angústia de morte, que só aumenta com a ascensão da liberdade na longa escala gradativa do catálogo do ser. Pode-se dizer que, para Jonas, a angústia é angústia que se carrega como fardo constante na luta contra a morte. E, nesse sentido, há de se entender que a morte é, de fato, um fardo, e isso não pode ser diferente para um ente mortal.
Mas a par do "fardo da mortalidade", e apesar dele - isto é, sem se negar seu caráter de "fardo" -, é preciso perguntar, por outro lado, se prolongar indefinidamente a vida no sentido de uma virtual imortalidade é, de fato, melhor do que uma vida mortal? A resposta a essa pergunta pode ser pensada a partir de dois planos: desde a perspectiva do bem comum da humanidade, assim como desde aquela do bem individual. Fiquemos primeiro com o plano do "bem comum da humanidade". Aqui, geralmente, três formas de críticas são levantadas contra aquilo que se pode chamar mesmo de "cruzada médica contra a morte” (Kass, 2004, p. 261).

Antes de tudo, levanta-se a questão da segurança quanto às consequências do uso de tecnologias de imortalização. Baseado na biologia evolucionista, Glannon (2002) defende que existe uma boa explicação evolutiva para a senescência e a mortalidade. Para o autor, a seleção natural permite mutações que causam doenças em uma idade mais avançada, mas reduz a um mínimo o aparecimento dessas mutações num período inicial de vida, o que oferece uma vantagem reprodutiva para os organismos humanos, já que, assim, eles podem transmitir seus genes sem maiores problemas para sua descendência. O prolongamento da vida poderia alterar, entretanto, o curso da seleção natural, pois a modificação genética de telômeros e a reconstituição das stem cells podem favorecer um maior número de mutações deletérias no início da vida, resultando em um dano para as futuras gerações, ao torná-las mais expostas a doenças e mortalidade prematura. Desse modo, pensa Glannon (2002, p. 341), "se se aceitam os princípios da biologia evolucionista, então a possibilidade que estou levantando deveria nos fazer interromper de forma temporária antes de desenvolver e implementar tecnologias de prolongamento da vida em larga escala.” É, certamente, uma atitude ingênua lançar sobre Glannon (2002, p. 344) a crítica de que a biologia não oferece orientação alguma para a moral. Pois, aqui, o dado biológico não aparece como oferecendo um dever, mas, antes, uma orientação sobre o que nós devemos julgar como melhor ou pior para as futuras gerações. Glannon 
diz explicitamente: "razões biológicas poderiam influenciar as razões morais no que concerne como deveríamos respeitar os interesses das pessoas no futuro em não serem prejudicadas". É bastante claro que o que Glannon defende é uma aplicação do princípio de precaução (PP). E, nesse sentido, o argumento se vê rodeado pela controvérsia instaurada pelo que os não partidários do PP chamam de o "paradoxo da precaução" (Harris; Holm, 2002, p. 356): "o cuidado [caution] que deveria nos fazer interromper de forma temporária acaba causando o dano que não deveríamos permitir ocorrer". O paradoxo, portanto, seria que a precaução contra o dano causa dano - pouco importando se esse dano é pensado positiva ou negativamente. ${ }^{2}$ Não se pode deixar de salientar que os não partidários de PP reclamam aí o fato de que os proponentes de PP superestimam os riscos e rebaixam o valor dos benefícios. Parece, entretanto, uma enorme injustiça com a consideração da precaução como princípio moral quando considerado como um princípio de tudo ou nada, como é o caso dos autores referidos. Acredito que uma distinção mais moderada dos vários tipos de PP, como a que se encontra em Clarke (2009), é altamente recomendável. Aí o PP não aparece como um "não" a toda possibilidade de desenvolvimento técnico, mas exige apenas maior cuidado nos passos tomados em relação a esse desenvolvimento - e esse me parece ser justamente o ponto de Glannon, quando fala de uma interrupção temporária. Mais ainda: como bem observou Hugh Lacey, uma versão moderada de PP pode, inclusive, jogar não contra a ciência, mas caminhar na direção de "enfrentar a crescente subordinação da pesquisa científica aos interesses das corporações e, assim, constituir uma força para

${ }^{2}$ Para Manson (2002, p. 272), a precaução também implica, por si mesma, possíveis danos. A observação do autor tem o mesmo sentido da objeção que se pode fazer à aposta de Pascal, tendo-se em vista a possibilidade de existência de muitos deuses - ou, pelo menos, de um deus diferente do de Pascal - e considerando-se também o sofrimento da ascese. Já para Sunstein (2005, p.29), a precaução "poderia muito bem privar a sociedade de benefícios significativos e, portanto, produzir, sérios danos". Em relação ao argumento de Manson, a objeção de Sunstein acentua o impedimento a um benefício, ao que o dano aparece não como algo que sofremos ou perdemos, mas como algo que deixamos de ganhar (ex. um novo remédio). repensar e reafirmar os aclamados valores nos quais descansa a autoridade da ciência: objetividade, neutralidade e autonomia" (Lacey, 2006, p. 388). Essas poucas considerações salientam a importância, de fato, da segurança para pensar a aplicação das novas tecnologias, mas estão longe de afastar a controvérsia em torno da precaução que se reclama em relação a elas - principalmente quando o benefício em questão é a "vida eterna”. Nesse sentido, a reivindicação de segurança tem um resultado duvidoso para os nossos propósitos, e acreditamos que a questão pode ser resolvida de maneira mais segura levando-se em consideração outros aspectos que, de todo modo, nos parecem mais fundamentais.

Como segundo motivo, fala-se das possíveis más consequências sociais. Levantam-se, por exemplo, questões relacionadas à política internacional e interna. Pensa-se que as mulheres representarão um grupo de maior participação eleitoral em função de sua maior expectativa de vida. Ainda que as consequências não sejam claras, sabe-se que isso implicaria, provavelmente, uma menor adesão a algum tipo de intervenção militar. Mais ainda: a própria disponibilidade de pessoal militar encolherá (cf. Fukuyama, 2003, p. 74-75). O que aparentemente parece ser um problema para o referido autor se apresenta como a solução para aqueles que desejam - ou, devemos dizer, sonham - com a paz perpétua, um sinônimo, portanto, de boa consequência. Numa direção bastante parecida Binstock (2004) mostrou que as tecnologias de prolongamento da vida podem gerar o aparecimento de uma nova coorte, os "mais velhos prolongados", e isso afetaria a política, porque aumentaria a já maior participação de voto da população mais velha. Mas: a) medidas de controle podem ser introduzidas para conter uma "maioridade de voto", e b) uma população envelhecida não significa homogeneidade em termos de decisão eleitoral. Teme-se também que as tecnologias de prolongamento da vida gerem maiores gastos com seguridade social. Fukuyama (2003, p. 73), por exemplo, salienta que, no Japão, o que hoje já apresenta uma relação de quatro trabalhadores para um aposentado se tornará, em breve, uma proporção 
de dois trabalhadores para um aposentado. Resultado intrigante dessa possível má consequência social resulta do contra-argumento que sempre lhe é dirigido, a saber: uma vez que o sonho é uma vida prolongada sem os reveses e as mazelas da velhice, a aposentadoria poderia ser adiada. Mas, nesse sentido, permanece um paradoxo: um dos resultados do fim do envelhecimento é que isso geraria a extensão da aposentadoria ou do trabalho indefinidamente e há de se ter sérias dúvidas quanto à desejabilidade de ambas as coisas (Temkin, 2011, p. 362). De qualquer forma, toda a discussão, neste ponto, pode se expor à controvérsia concernente a uma revalorização de novos papeis sociais para as pessoas idosas: sugere-se, por exemplo, que

[...] coletivamente, a extensão do tempo de vida oferece para a sociedade na qual ela ocorre o valor de uma aumentada experiência, know-how, labor, relacionamentos afetuosos, e assim por diante - isto é, tudo que as pessoas (mais) velhas e saudáveis podem contribuir (Overall, 2011, p. 391).

É bem verdade que a descrição de Overall sobre os idosos saudáveis certamente goza de uma dose exageradamente otimista - para não dizer retórica -, uma vez que ela destaca apenas características positivas e não ameaçadoras. Não obstante, parece (ou é mais) provável que os mais velhos, ao estarem de posse do poder que conquistaram durante sua já longa vida, busquem conservar acirradamente tal poder (Mordacci, 2011, p. 416; Fukuyama, 2003, p. 75-77), e, nesse sentido, muito antes de "relações afetuosas", devemos esperar um verdadeiro aumento da competitividade intergeracional que, desde o início, pende na balança a favor dos já apoderados, isto é, dos mais velhos. Muitas outras preocupações assolam o imaginário relacionado às más consequências sociais. Explicitamos aquelas que, de algum modo, sempre aparecem nas discussões sobre o tema. Acreditamos mesmo que o problema resultante das implicações da aplicação das técnicas de imortalização para a sociedade humana é um dos principais pontos de crítica, mas, em todas elas, a questão sempre recai, por fim, sobre a situação ideal em que os riscos não se apresentam, isto é, em que as complicações foram resolvidas a um mínimo aceitável. Aqui, a discussão, além de estar sujeita a projeções apenas possíveis, mas não necessárias, ainda está exposta à contra-argumentação dos "proponentes da imortalidade", que podem perfeitamente lançar mão da ideia de planejamento, bem como se valer de outros tipos de atenuações dos possíveis problemas. Enfim, tanto no que toca ao problema da segurança quanto no que se refere ao problema das más consequências sociais, uma resposta mais segura e firme parece escapar com a evocação de condições ideais de temperatura e pressão. A ignorância aparece apenas como um freio para a ação, que pode ser retomada sob a tutela de novas e mais confiáveis condições de exequibilidade.

E o que dizer da justiça? Por acaso encontraríamos aqui uma melhor alternativa? As acusações relacionadas à justiça distributiva aparecem no topo da lista, já que se imagina que o prolongamento da vida seria algo caro, ao acesso de uns poucos. É, de fato, inegável que, devido ao alto custo das tecnologias de imortalização, algumas populações seriam favorecidas, criando o que Harris (2007, p. 62), por exemplo, chama de "populações paralelas", isto é, populações de pessoas mortais e imortais vivendo paralelamente. E, como bem percebeu Barazetti (2011, p. 343), não se trata apenas de um aumento da diferença da distribuição das oportunidades de acesso à nova tecnologia, mas também da distribuição dos recursos ambientais entre as populações e países, já que, com a queda da taxa de mortalidade, maior será a população e maior o consumo dos recursos ambientais. Desse modo, alguns pensam que, em função da injustiça - ou melhor, do aumento da justiça - em decorrência das tecnologias de prolongamento da vida, deve-se negar as tecnologias de prolongamento a todos. A censura da nova tecnologia por uma questão de justiça é rebatida, primeiro, com a atenuação do caráter indesejável e até mesmo injusto [unfair] de tal cenário pela valorização dos benefícios que as tecnologias de pro- 
longamento da vida também trazem. Assim, Harris, por exemplo, defende o seguinte:

[...] se a imortalidade e o aumento da expectativa de vida é um bem, é eticamente duvidoso negar bens palpáveis para algumas pessoas porque não podemos os oferecer para todos. E essa injustiça [unfairness] não é simplesmente contingente, uma função deplorável, mas em princípio extinguível, por falta de recursos. Sempre vão existir circunstâncias nas quais não podemos prevenir danos ou fazer bem a todos, mas ninguém certamente pensa que isso nos dá uma razão para recusar a prevenir o dano a alguém em particular (Harris, 2007, p. 62).

Ademais, os defensores das tecnologias de imortalização afirmam que essas diferenças de acesso acontecem com toda nova tecnologia, mas que, com o tempo, elas se disseminam por toda parte, uma vez que tendem a se tornar mais baratas. Uma grande estranheza a respeito da reclamação da justiça a esse respeito é o fato de que a diferença na distribuição dos anos de vida foi uma realidade constante da existência humana, mas nunca reclamada. Com as tecnologias de prolongamento da vida, assistimos ao primeiro fato, na história, em que se questiona a justiça ou injustiça de uns viverem mais do que outros.

Somado a esta estranheza, outro aspecto do problema gera perplexidade: a justiça aparece como um motivo tanto para a censura e contenção das técnicas de prolongamento da vida como para o uso dessas mesmas técnicas. Pois, se, por um lado, elas podem ser fontes de injustiça, por outro, elas seriam o próprio veículo da justiça. Essa última posição defendem, principalmente, Buchanan et al. (2000) e Overall (2009) - para ficar com os argumentos mais influentes. ${ }^{3}$ Para Christine Overall, em especial, a aplicação das tecnologias de prolongamento do tempo de vida deve levar em consideração a categoria de identidade social para se pensar o acesso, o significado e o valor de tais

${ }^{3}$ Abaixo, discutiremos brevemente apenas o caso de Overall (2009), porque, ao contrário do que acontece com a discussão que se encontra em Buchanan et al. (2010), que se concentram numa defesa de aplicações mais relacionadas ao combate de "incapacidades" (disabilities) do que propriamente ao enhancement do tempo de vida, ela ataca diretamente o problema das tecnologias de prolongamento da vida. técnicas, e as implicações disso para a política. Ao invés de uma "justiça meritocrática", devemos pensar em termos de uma "justiça compensatória", pois, segundo ela,

[...] podemos ter algumas obrigações de compensar a loteria social que torna certas filiações a um grupo [group memberships] uma deficiência [liability] [...] [Ao contrário], poderíamos bem ter mais obrigação de oferecer um enhancement do tempo de vida para membros de alguns grupos do que para membros de outros (Overall, 2009, p. 337)

Mas, se bem se percebe, aqui a discussão perde todo o sentido, pois, como destaca Mordacci,

[...] o ponto em questão aqui não é se deveríamos 'estender o número de vidas longas' (que pode ser considerado um dever de justiça), mas se deveríamos 'estender o tempo de vida humano', o que é um problema diferente: mais vidas longas não implica vidas mais longas (Mordacci, 2011, p. 415, grifo nosso).

Posto isso, gostaríamos de voltar a um ponto já salientado e que poderá nos conduzir a uma última possibilidade da discussão sobre a justiça. Refiro-me ao argumento que considera que devemos negar o acesso às tecnologia de prolongamento de vida a todos (mas vale também para qualquer ideia de "justiça compensatória"). O argumento tem, em si mesmo, uma lógica estranha. Se, de fato, é uma injustiça que alguns tenham acesso à imortalidade terrena e outros não, é porque, de fato, pensam que a imortalidade como tal não oferece problemas de outro tipo que não aquele concernente à justiça - isto é, ao igual acesso a uma vida prolongada indefinidamente. Mas, se é assim, uma opção que parece muito mais aceitável seria afirmar, como o faz Bostrom (2004, p. 503), que “... uma das formas de contrabalançar a desigualdade trazida pelas tecnologias de enhancement seria subsidiá-las ou fornecê-las de forma gratuita para os descendentes de pais pobres". Mas podemos esperar um melhor resultado com essa opção de se subsidiar as tecnologias de imortalização para todos?

Para responder ao problema, utilizaremos um experimento mental - na verdade, a simples 
suposição de uma situação ideal - para analisar o que tal situação nos oferece como indicação para a pergunta pelo “bem comum da humanidade”. Em uma situação ideal de temperatura e pressão, o que diríamos, do ponto de vista moral, se, em termos de segurança, consequências sociais e justiça, a "imortalidade" terrena não apresentasse problemas. Isto é: se, por um lado, todos os riscos inaceitáveis (decorrentes da aplicação técnica) para as futuras gerações fossem sanados, e se, por outro, com um planejamento eficiente da estruturação social, as mazelas fossem atenuadas de modo razoável ao nível do que já presenciamos, e, por fim, se a todos fosse dado acesso ao benefício "eterno" da vida? Atendendo a tais requisitos, não seria ela reprovável moralmente? Num tal cenário, poderíamos dizer que o prolongamento indefinido da vida é moralmente aceitável? Ora, é fácil de ver que, no caso das tecnologias de imortalização, mesmo numa situação ideal como essa, estaríamos diante também do caso de maior irresponsabilidade moral, pois, uma vez que todos tivessem acesso a uma "imortalidade terrena”, a natalidade se tornaria inconcebível. Como bem salientou Jonas,

[...] uma vez que se percebe que a mortalidade não é senão o outro lado do perene florescer da 'natalidade' [...] na escala demográfica, o preço de uma idade estendida precisa ser uma diminuição proporcional da reposição (Jonas, 1984a, p. 49).

Com o termo "natalidade", Jonas segue bem de perto aqui sua amiga Hannah Arendt, ${ }^{4}$ que não por acaso, em seu Diário Filosófico (no aforismo 61, de Outubro 1969), afirma: “... o desejo de imortalidade terrena é blasfêmia, não porque queira eliminar a morte, mas porque nega o nascimento" (2006, p.722). Assim, para além do problema da justiça, que, nesse caso, se torna mesmo imoral, o “cerne do problema”, aqui, se refere ao valor intrínseco da natalidade. ${ }^{5}$

${ }^{4}$ Jonas, inclusive, escreveu um ensaio sobre Arendt, onde ele presta elogio ao conceito de natalidade elaborado por sua amiga em The Human Condition (cf. Jonas, 1977, esp. p.30-31). Sobre o conceito de natalidade em Jonas, ver também os trabalhos de Jean Greisch (1994, esp. p.82-89) e de Nathalie Frogneux (2004).

${ }^{5}$ Um importante aspecto da questão foi explicitado por Vittorio Hösle, quando destaca que a teoria da justiça,
Mas o que exatamente há de "blasfêmia" na extinção da natalidade? Para se entender corretamente o sentido da posição de Jonas, é preciso entender o verdadeiro significado da natalidade. Logo de saída, há que se entender que ela “... é um atributo da condição humana tão essencial quanto a mortalidade" (Jonas, 2009, p. 277). Mas o que especificamente ela atrela a tal condição? Em uma entrevista concedida a Ângelo Bolaffi, para o jornal italiano L'Unità, Jonas nos diz:

o especificamente humano, diferentemente da célula que se autorreproduz por divisão ao infinito, é a diferenciação dos sexos, a reprodução e, por conseguinte, a morte. O sentido da morte é a autorrenovação da vida e, portanto, a ulterior autodiferenciação, o desenvolvimento (Jonas, 1991b, p. 17).

Com esses três termos - autorrenovação, autodiferenciação e desenvolvimento-, Jonas resume o que a natalidade representa como resposta essencial à mortalidade. Mas o que cada um deles representa especificamente? Enquanto autorrenovação da humanidade, a natalidade precisa ser pensada como emergência de um novo começo:

[...] a juventude é nossa esperança, ela é a promessa eterna para que a vida mantenha sua espontaneidade. Com seu início sempre renovado, com todas as suas loucuras e hesitações, é o jovem que sempre renova e assim mantém vivo o significado do espanto, da relevância, da incondicionalidade, do compromisso supremo, que (sejamos francos) adormece em nós à medida que ficamos mais velhos e cansados. (Jonas, 1980, p. 182) $)^{6}$.

Essa afirmação não dever ser lida como se Jonas estivesse defendendo a juventude como um

tal como a concebe John Rawls, "tem grandes dificuldades de justificar o princípio da justiça inter-geracional; ele precisa - pelo menos em uma de suas linhas de raciocínio - assumir um desejo factual pela descendência, que não é em si mesmo fundamentado" (Hösle, 2004, p.225n15). É importante salientar a observação de um comentador japonês do pensamento de Jonas: em função da consciência intergeracional que marca a cultura japonesa, "é mais persuasivo no Japão insistir na ética intergeracional baseada no conceito de responsabilidade do que na teoria rawlsiana do contrato social" (Shinagawa, 2012, p.26).

${ }^{6} \mathrm{Na}$ mesma direção do argumento anterior, mas levemente distinto, como salienta Temkin (2011, p.364), essa mesma ideia aparece no consolo proclamado no Yisgor Service do Dia Judaico da Expiação: "[...] se alguns mensageiros fossem enviados até nós com a oferta de que a 
simples "mecanismo de defesa" contra o tédio da velhice. A questão aqui não é o tédio propriamente, pois, se bem se percebe, Jonas se refere ao plano do coletivo e não do individual. Antes é a juventude considerada em seu próprio valor e isso a tal ponto, que, em uma outra entrevista, Jonas pensa sobre o significado da juventude:

O que é, então, o jovem? O que é, então, a criança? Os olhos abertos [Augenöffnen] em um mundo ao qual esses entes ainda não viram e do qual precisam se apropriar, descobrir, e no qual eles mesmos precisam encontrar sua própria resposta. Esta é a fonte de eterna renovação no homem... A sorte é que sempre novamente nascem entes para os quais tudo é novo. Estes veem o mundo pela primeira vez. Isto abre novos horizontes. (Jonas, 1991a, p. 143-144, grifos nossos).

Aqui, "jovem” se torna mesmo uma nova categoria filosófica e aponta para a condição de possibilidade de renovação do mundo humano. A metáfora dos olhos abertos não é despropositada, mas visa a lembrar a perspectiva antropológica defendida já em The Phenomenon of Life (1966), onde a visão responde pela própria faísca do pensamento humano (cf. Jonas, 2001, p. 135-156). O nascer é o recomeço de uma nova abertura para a verdade do ser como tal. Trata-se de uma abertura em que a própria experiência da verdade está em jogo novamente.

Junto com a emergência do novo, a natalidade como auto-diferenciação da humanidade representa a oferta de "suprimento da alteridade como tal” (Jonas, 1984a, p.49; 1984b, p. 19). Portanto, ela atende à lógica da alteridade em detrimento da lógica do mesmo. Mais precisamente, o que se tem de entender é que

morte devesse ser abolida, mas com a única condição inseparável de que nascimentos também deveriam deixar de acontecer; se as gerações existentes tivessem a chance de viver para sempre, mas com o claro entendimento de que nunca mais existiria uma criança, ou um jovem, ou um primeiro amor, nem novas pessoas com novas esperanças, novas ideias, novas realizações, [... poderia a resposta estar em dúvida?” Roberto Mordacci percebeu bem, nessa mesma direção, que, para além das questões de más consequências sociais, as técnicas de prolongamento da vida têm como resultado o fato de que "ao mesmo tempo, a variedade de ideias, energia nova, e atividades criativas serão reduzidas" (2011, p. 414). Intrigantemente, o autor não desenvolve esse importante fato por concentrar sua atenção no problema da justiça. outra recompensa da 'natalidade' é também a de que cada um dos recém-chegados é diferente e único. A função da reprodução sexual é tal que nenhum de seus resultados é, em termos de constituição genética, a réplica de um antecessor e nenhuma réplica sequer será reproduzida consequentemente (Jonas, [1991] 2009, p. 277).

Como bem viu Jean Greisch, “[...] a natalidade exprime, assim, o fundamento ontológico da unicidade de cada indivíduo humano.” (1994, p.84). Nesse sentido, a busca pela imortalidade terrena apareceria como uma busca pelo mais conhecido e não pelo diferente. Essa mesma crítica Jonas já utilizara contra a clonagem, em seu "argumento existencial”, e aqui ele apenas a repete do ponto de vista da natalidade: o que está em jogo é a ideia de uma ipseidade sem prejuízo; agora, não no sentido individual apenas, mas na esfera da própria humanidade.

A autorrenovação e a autodiferenciação próprias da natalidade apontam, consequentemente, também, para o desenvolvimento da humanidade. Eis o que Jonas diz ser o verdadeiro escopo de sua reflexão:

[...] a ligação da mortalidade com a criatividade na história humana. Quem quiser, portanto, se comprazer com a colheita cultural das várias épocas em cada uma de suas facetas e não deseja passar sem elas, e mais claramente aquele que louva e advoga o progresso, deveria ver na mortalidade uma bênção e não uma maldição (2009, p. 278).

Destaque deve ser dado aqui à "colheita cultural das várias épocas”, e o que ele tem em mente são as mudanças políticas, sociais e mesmo intelectuais que o aparecimento de novos entes humanos pode acarretar - algo que ocorreria de modo muito mais lento sob pena mesmo de enrijecimento, caso esses novos seres não viessem ao mundo. Fukuyama percebeu bem o valor dessa colheita no que concerne ao aspecto intelectual:

[...] a sobrevivência de um 'paradigma' básico (por exemplo, keynesianismo ou friedmanismo), que molda a maneira como a maioria dos intelectuais e cientistas pensa sobre as coisas num momento particular, depende não apenas dos dados empíricos, como gostaríamos de acreditar, mas da sobrevivência física das pessoas que 
criaram esse paradigma. Enquanto elas se mantiverem no topo de hierarquias graduadas pela idade, como conselhos de avaliação de pares, comitês para o preenchimento de cargos e conselhos curadores de fundações, o paradigma básico permanecerá, em geral, praticamente inabalável (Fukuyama, 2003, p. 78). ${ }^{7}$

Não sem motivo a natalidade era, para Arendt, o milagre que salva o mundo ${ }^{8}$ e torna-se, por isso mesmo, uma tarefa da responsabilidade para Jonas. Não obstante, esse sentido do argumento de Jonas - o valor da natalidade como autorrenovação da humanidade e passo para um ulterior autodiferenciação e desenvolvimento da civilização -, de alguma maneira, não parece ter escapado a Harris, que, ao que lhe toca, parece tentar encontrar uma solução para o problema. Ainda que reconheça que "novas pessoas, novas ideias, e a possibilidade de um desenvolvimento humano continuado" são razões poderosas a se considerar, ele sugere, entretanto, num tom deliberadamente repulsivo [unpalatable], algo como uma "limpeza geracional [gerational cleansing]” (cf. Harris, 2004, p. 532; 2007, p. 69). "Isto - diz ele - envolveria decidir coletivamente quanto tempo, para as pessoas, é razoável viver em cada geração e tentar assegurar que o maior

${ }^{7}$ Regras de aposentadoria compulsória aparecem justamente para evitar a discriminação. Mas essas atitudes eram regras impessoais e discriminatórias e foram abolidas em muitos lugares dos EUA. Não obstante, por mais que a crítica ao preconceito ao idoso tenha entrado na lista da "correção política" junto com o racismo, sexismo, etc., Fukuyama afirma, entretanto, que há "[...] várias razões que fazem da sucessão das gerações uma boa coisa. A principal é que ela é um grande estimulante do progresso e da mudança." (p.77). Para Fukuyama, mesmo os paradigmas científicos tendem a se manter em função da influência de um determinado grupo que ocupa a posição de prestígio, o que, no caso de um maior prolongamento de vida, alargaria sua influência intelectual e do paradigma vigente.

${ }^{8}$ Em seu Diário, Arendt narra como lhe veio à cabeça a ideia do que viria ser o conceito de natalidade: inesperadamente, num concerto em Berlin, onde assistira a uma interpretação do Messias de Haendel. Como o conceito de natalidade poderia ter uma origem tão desconcertante como essa? No aforismo 12, de maio de 1952, ela nos revela: "O aleluia [no Messias de Haendel] só pode ser entendido desde o texto: nos nasceu um menino. A verdade profunda desta parte da lenda de Cristo se expressa em: todo começo é salvação; por meio do começo, por meio desta salvação, Deus criou o homem dentro do mundo. Cada novo nascimento é como uma garantia da salvação no mundo, é como uma promessa de redenção para aqueles que já não são o começo." (Arendt, 2006, p.200). Mais tarde, na conferência "Trabalho, Obra, Ação", diz ela: "[...] sem a ação, sem a capacidade de começar algo novo e, deste modo, articular o novo começo que número possível viva saudavelmente tal extensão [de tempo]" (Harris, 2004, p.532; 2007, p. 69). O desespero sofístico do argumento de Harris - que não pode ser considerado senão retórico - é patente: o homem que, nove páginas antes, em seu texto, aclamava a "imortalidade" como o "santo graal do melhoramento", parece agora se conformar com apenas um "período justo [fair innings]" de vida. Para fazer uso do estilo um tanto sarcástico do próprio Harris, é preciso mesmo imaginar a mesa de tal acordo de "limpeza geracional”, e, principalmente, o momento em que o médico dará a notícia ao seu pobre paciente mortal: "Veja bem dirá o médico -, aqui está o seu elixir da juventude, mas, em acordo firmado pelos homens de bem de nosso povo, mesmo que o senhor não venha a sofrer um acidente e mesmo que esteja em plena saúde (graças às proezas alcançadas por nossa medicina arrojada), ao cargo de 200 anos terás que dar cabo a tua vida para que se cumpra a 'limpeza geracional"” do nosso povo.

Basta imaginar tal cena para perceber o absurdo da sugestão. Também Christine Overall (2005, p.85) explicitou grande ceticismo quanto aoargumento de Harris frente a tal "limpeza geracional”, pois, segundo ela, isso "compartilharia com a limpeza étnica o assassinato deliberado de centenas, talvez milhares, de pessoas, cuja única 'culpa' foi a de que eles foram considerados um fardo e foram preteridos na sociedade."

Apenas com o argumento apresentado até aqui, Jonas já teria aberto um campo enorme para a resposta do bem comum da mortalidade como "contrapartida essencial” da natalidade. Mas precisamos ainda nos voltar para o segundo plano da discussão, aquele da mortalidade como "bem individual para o Eu (self)”. Pois notem: a defesa do valor da natalidade só se aplica à consideração de uma imortalidade terrena estendida a toda a humanidade - isto é, numa situação em que o remédio estivesse disponível a todos. Isso não precisa ser assim. Poder-se-ia imaginar que apenas a al-

entra no mundo com o nascimento de cada ser humano, a vida do homem, que se estende desde o nascimento até a morte, seria condenada sem salvação." (Arendt, 1995, p. 107; cf. Arendt, 1998, p. 177). 
guns poucos afortunados seria permitido conceder o benefício eterno. Assim, é preciso perguntar se tais afortunados teriam, de fato, uma boa fortuna. Ora, já muitas considerações foram também discutidas e têm sido discutidas para negar a imortalidade, inclusive, como "bem individual", e acredito que, dentre as várias razões levantadas, pelo menos uma não nos parece deixar muita margem quanto à resposta. Vejamos.

De saída, o problema, como bem mostrou Jonas, pode ser associado primeiro à questão de "se uma vida curta, mas plena, é preferível a uma longa vida na inatividade." (Jonas, 1984c, p. 81). Nesse caso, ainda que a maldição do "não-podermorrer" exemplificada nos "imortais" de Jonathan Swift seja mais sagaz e instrutiva do que o suposto privilégio de um "não-ter-que-morrer" - tal como o louvava, por exemplo, Bernard Shaw - ela sofre, entretanto, da falha de que a tais imortais " [...] é negada a morte, mas não lhes são poupadas as enfermidades da velhice e as indignidades da senilidade.” (Jonas, 2009, p. 279). Mas, ao se excluírem os males da senilidade, então, uma vida breve continua ainda sendo preferível a uma longa vida? Tomando como exemplo a personagem Elina Makropulos, Bernard Williams, já em 1973, se decide pelo fato de que o problema seria agora o tédio de uma vida imortal. Aqui, Jonas está do lado de Williams, pois se lembra desse novo caso da maldição do "não-poder-morrer", onde não entram em jogo os males da senilidade: "Ahasver, o judeu imortal, que nada desejava mais ardentemente do que poder morrer.” (Jonas, 2009, p. 142). Não obstante, creio que, além das difíceis questões que se levantam, como o próprio Williams anteviu, a respeito da "constância do caráter", é preciso dizer que o argumento do tedium vitae é esfacelado de um só golpe com o belíssimo conto Viver!, de Machado de Assis. Nele, o maior escritor de nossa língua explora justamente o drama da figura lendária de Ahasver, que fora condenada a viver errante até a Parousia. O quadro maravilhosamente pintado é o do homem - talvez o único que conhece o verdadeiro tédio. E, apesar disso, quando o sagaz Prometeu lhe promete a terra pro- metida, o que vemos acontecer? A recusa daquele que, momentos atrás, amaldiçoava veementemente sua própria vida miserável e tediosa? Não. Vemos, antes, os olhos flamejantes daquele que diz "Eu quero"! A conclusão de Machado de Assis pode, então, ser resumida com essa simples zombaria de duas águias que de longe avistavam Ahasver:

[Uma das águias diz:] Ai, ai, ai deste último homem, está morrendo [uma referência à Parousia] e ainda sonha com a vida [o céu pintado por aquele que o promete: Prometeu]. [E a outra completa:] Nem ele [o judeu imortal] a odiou tanto, senão porque a amava muito (Assis, 1997, p. 569).

O que Machado nos ensina aí é que a vida humana comporta essa bela ambiguidade segundo a qual ela, contra todos os horrores, parece sempre dizer não ao não-ser. Pelo mesmo motivo, também não nos parece alcançar um resultado muito melhor o argumento de Richard Norman (1996) sobre a morte como um limite orientador para as nossas projeções de vida - argumento que não é senão uma nova versão do memento mori, ao qual também Jonas já prestara elogio ${ }^{9} \mathrm{e}$ que foi mais bem estilizado posteriormente com as "virtudes" da mortalidade destacadas por Leon Kass (2004).

Se, então, o tedium vitae e a sabedoria do memento mori não bastam para contestar a meta da imortalidade terrena ativa, isso não significa, entretanto, que estamos diante de um impasse entre o que supostamente seria o bem individual da imortalidade terrena e o bem da mortalidade para humanidade. Com um experimento mental brilhante, Jonas ofereceu em The Burden and Blessing of Mortality (1991) uma direção para responder ao problema: ${ }^{10}$

[...] somos seres finitos - diz ele - e mesmo que nossas funções vitais continuem intactas, exis-

" $[$ [...] o papel do memento mori deveria ser considerado para a vida individual, e para o que sua atenuação indefinidamente pode provocar a tal vida. Talvez um limite inegociável para nossa expectativa de vida seja necessário para cada um de nós como um incentivo para contarmos nossos dias e fazê-los contar" (Jonas, 1984a, p. 50).

${ }^{10}$ Parece-me que o próprio desenvolvimento de um novo argumento contra o valor da imortalidade terrena para o indivíduo demonstra que o próprio Jonas não estava de todo satisfeito com as sabedorias do memento mori e do tedium vitae. 
tem limites para o que nossos cérebros podem armazenar e continuar acumulando. É a parte mental de nosso ser que, mais cedo ou mais tarde, exigirá descanso, [pois] mesmo que os magos da biotecnologia inventem truques para manter a máquina do corpo funcionando indefinidamente [...] [eles] também teriam que limpar a mente periodicamente de seus antigos conteúdos (como um computador) para que possam dar lugar aos novos... A grande verdade de nossa finitude é a de que, seja lá como for, só poderíamos continuar a viver ilimitadamente ao preço ou da perda do passado, e com ele nossa real identidade, ou apenas vivendo no passado e, portanto, sem um verdadeiro presente. Não poderíamos seriamente desejar nem uma coisa nem outra [...] (Jonas, [1991] 2009, p. 279-80).

Contra esse argumento, entretanto, Harris afirma o seguinte:

[...] é fácil perceber - diz ele - que a identidade pessoal não é algo necessário para um desejo coerente de sobrevivência indefinida. Suponha que 'Matusalém' tem três identidades, A, B, e C, originando-se verticalmente até o futuro e que $\mathrm{C}$ de nada se lembra da vida de A. Mas suponha que isso também é verdadeiro: A quis ser $B$, que se lembrará de ser A; B se tornará C, que se lembrará de ser B. (Harris, 2007, p. 65).

Contra Harris, entretanto, é preciso dizer: primeiro, não é tão fácil ver que a identidade pessoal não seja algo necessário para se desejar continuar a viver indefinidamente. Se quero continuar a viver, o quero sendo eu mesmo e não outra coisa. Mas, então, o que dizer do que afirma Harris? Para mostrar os problemas envolvidos nessa posição, é preciso considerar dois pontos: (1) ela se baseia em uma falsa compreensão do que é a identidade pessoal, e, por isso mesmo, (2) dá a falsa impressão de que a identidade pessoal não é necessária para o desejo de se continuar a viver gerando, inclusive, problemas nefastos do ponto de vista moral. Para tanto, consideraremos criticamente a concepção sobre a identidade pessoal elaborada por Derek Parfit (1987), que não apenas é a que está por trás do argumento de Harris, mas tem também a maior influência nas discussões sobre o problema à mão.

Parfit parte de uma crítica do que considera ser a "versão padrão" da identidade pessoal, a saber: o critério do espaço-tempo. Parfit levanta três problemas: (1) um objeto pode ser dividido em um momento e depois remontado e continuar a ser o mesmo; (2) pode ter suas peças substituídas e continuar a ser o mesmo; e (3) a indeterminação de nossos conceitos deixa indeterminada também a certeza quanto aos objetos de que são conceitos. Isso leva à necessidade de adoção de critérios pragmáticos. A questão de se a coisa é a mesma é vazia. A versão-padrão se aplica mais a objetos físicos. No caso da identidade pessoal, é o aspecto psicológico (memória, emoções, etc.) que importa, de modo que a identidade pode permanecer, mesmo que se ocupe outro corpo, ou mesmo, como em certas concepções religiosas, independentemente da existência corporal. Assim, ao invés de continuidade física, o critério é a "continuidade psicológica”, que, no caso de Parfit, é pensada em termos de "conexão psicológica”. Aqui aparece o que defendia explicitamente Harris seguindo Parfit: se B (quase) se lembra e (quase) quer o que A experimentou e queria, então B e A estão ligados psicologicamente. ${ }^{11}$

A conectividade psicológica pode ser pensada de uma perspectiva tanto não reducionista (dualista ou não) como reducionista. A primeira concebe a pessoa (como sujeito psicológico que persiste) como ente irredutível. E a outra pensa que a pessoa pode ser reduzida à existência do cérebro e do corpo. Para o fisicalista, o psicológico depende da causa normal, que é o suporte material, portanto, de sua continuidade. Mas Parfit acredita que isso não é necessário, antes é a organização da matéria e não a matéria mesma aquilo que determina a continuidade ou conectividade psicológica. Um exemplo pode nos ajudar: numa cirurgia em que parte do cérebro é extraída, mas uma cópia dessa parte (sem o problema que o outro apresentava) é colocada no lugar, sendo capaz de manter a memória, então o processo mnêmico seria tão bom quanto o original, e a continuidade psicológica não dependeria do mesmo suporte material, tal como acontece no metabolismo. Nesse sentido, em vez do "continuador mais próxi-

${ }^{11}$ Parfit destaca o "quase” porque não se pode tratar, de fato, de memória e de intenção, já que tais conceitos implicam, em si, a identidade. 
mo” de Nozick (1981), o que determina a futura identidade pessoal é a continuidade psicológica (formal, e não material) do indivíduo passado.

Agora, uma vez que se entende tudo isso, não é difícil perceber por que uma simples conexão psicológica serve de bom grado, por exemplo, a Parfit - e também a Harris - e seus propósitos, podendo, inclusive, substituí-lo no futuro. Mas notem: de substituição se trata de fato, e não de continuidade. Para que se entenda que aí não temos verdadeira identidade, mas sua falência, oferecemos um exemplo: imaginem que uma certa pessoa possui determinados projetos, memórias, etc. Essa pessoa tem também um grande admirador, que conhece esses projetos, conhece a vida dessa pessoa nos seus mais intricados momentos (suas “memórias"), etc. Se a primeira pessoa sofresse um grave acidente, perdendo boa parte da memória bem como seus projetos, mas seu admirador levasse a cabo, por conta própria, tais projetos, o que poderíamos dizer? O admirador, enquanto leva adiante o que aquele a quem admira não pode, adquire a identidade daquele que já não a pode mais levar adiante? Ou apenas o corpo que resta à primeira pessoa garante-lhe, perante seu admirador e imitador, o lugar de honra de ser si mesmo? Também Christine Korsgaard percebeu o cerne do problema, pois, na concepção de Parfit, diz ela:

[...] é a continuidade e não a unicidade que realmente importa. Pois se o aspecto essencial de uma pessoa é formal e copiável, então em princípio parece que poderíamos fazer duas cópias igualmente boas de uma pessoa. Ambas seriam formalmente contínuas com a pessoa original; cada uma delas teria as memórias, o caráter, as ambições e os amores da pessoa; cada uma delas acreditaria, ou pelo menos sentiria, que ele é a pessoa original. Nesse caso , a questão sobre qual deles é a mesma pessoa que a original é uma questão vazia. Nesse caso, e pode não importar, ou pode depender de circunstâncias, o que deveríamos dizer a respeito disso. E assim a identidade pessoal não é importante. (Korsgaard, 1989, p. 107$)^{12}$

${ }^{12}$ Também Roberto Marchesini, transhumanista convicto, admite o resultado a que chegamos: “[...] não se pode negar uma correspondente queda [caduta] total ou parcial da identidade. Ressuscitar de modo tecnológico significa principalmente perder a própria identidade [profilo] ou, melhor, comprometer a possibilidade de ter uma identidade" (2005, p. 500).
Mesmo que aquilo que Parfit considera como continuador, na conexão psicológica, precise de uma conexão direta (e sobre o que ele quer dizer com “direta” não sabemos ao certo), não é completamente satisfatório. Como bem observa Korsgaard, não é óbvio que

ter os traços de memória de outra pessoa copiados em nosso cérebro seja um modo mais direto de conhecer algo do que ser informado. Sem dúvida ele teria um sentimento [feel] mais direto dela, pois seria sentido como uma memória, mas isso não faria diferença alguma para o que importa (Korsgaard, 1989, p. 107, n14).

De qualquer forma, a ideia de uma "continuidade” via conexão psicológica é certamente uma reinvenção mais sagaz do que a antiga ideia da hereditariedade como imortalidade, afinal ela carrega meus propósitos adiante de forma que filho algum o poderia. Não obstante, trata-se de uma imortalidade irreal e mais escrava também, pois o meu "continuador" vem ao mundo apenas em função de uma espécie de missão - completar minhas intenções, meus projetos, meu lugar e papeis como pai, esposo etc. Assim, a solução de Parfit - a qual Harris segue explicitamente ${ }^{13}$ - levanta a pergunta pelo valor e dignidade daquele que "continua” com parte da minha vida psicológica, que, já de saída, se encontra numa situação de prejuízo quanto à sua ipseidade em relação aos demais entes, como no caso da clonagem. Ademais, estaríamos de novo diante de uma situação que implicaria a negação e muito provavelmente a abolição da natalidade-e isso já tínhamos considerado como inaceitável.

Para terminar, gostaríamos apenas de deixar destacado tanto o resultado a que chegamos como alguns problemas que deixaremos apenas indicados como questionamentos para posteriores reflexões. O resultado pode ser facilmente resumido com esse pequeno verso:

A vida - eis o que quero!

A vida - eis o que não posso!

Outrora, a natureza

Agora, moral ofensa.

${ }^{13}$ Cf. Harris (2007, p. 215, n7). 
O que ele expressa é um paradoxo: de um lado, a vontade imensa do viver alimentada pela técnica! De outro, a impossibilidade colocada pelo dever moral de morrer! Dever esse alicerçado não num suposto bem em si da mortalidade, mas no bem que é a natalidade. Ao ser promessa de um novo começo da humanidade, ela e apenas ela pode conceder mais sentido à nossa mortalidade - pelo menos mais sentido do que uma vida indefinida que se esvaece na perda da identidade, algo que tem tão pouco sentido quanto morrer! - e, nesse sentido, exigir de nós a aceitação de nossa finitude.

Quanto às questões que ficam, direi primeiro: uma vez que a perspectiva de imortalidade se expõe a todas essas contradições discutidas - e não são poucas -, resta ainda saber se mesmo a busca positiva de um considerável aumento da extensão da vida é desejável. A questão aqui seria: quanto tempo é o bastante? Ademais, ao se afirmar o bem da mortalidade, afirma-se a morte como única meta final da vida humana? Ou há ainda lugar para se pensar a ideia de imortalidade numa vida mortal?

Recebido para publicação em 20 de outubro de 2012 Aceito em 04 de novembro de 2012

\section{REFERÊNCIAS}

ARENDT, Hannah. Diario filosófico: 1950-1973. Barcelona: Herder, 2006. 2 v.

Labor, trabajo, acción: uma conferencia. In: 1996. p.89-107.

De la historia a la acción. Barcelona: Paidós,

ASSIS, Machado de. Viver! In: COUTINHO. Afrânio De. (Org.) Obra completa. Rio de Janeiro: Ed. Nova Aguilar, 1997. p. 563-569.

BARAZETTI, Gaia. Looking for the fountain of youth. In: SAVULESCU, Julian; MEULEN, Ruud ter; KAHANE Guy. Enhancing human capacities. Chichester: WileyBlackwell, 2011. p.336-349.

BINSTOCK, R. H. The prolonged old, the long-lived society and the politics of age. In: POTT, S. G.; BINSTOCK, R. H. The fountain of youth: cultural, scientific, and ethical perspectives on a biomedical goal. Oxford: Oxford University Press, 2004. p. 362-386.

CALLAHAN, Daniels. The desire for eternal life: scientific versus religions visions. The 2002-03 Ingersoll Lecture. Harvard Divinity Bulletin, Cambridge, Havard, v.31, n. 2, p.13-17, spring, 2003.
CLARKE, Steve. New technologies, common sense and the paradoxical precautionary principle. In: SOLLIE, P.; DÜWEL (Ed.) Evaluating new technologies. The International Library Of Ethics, Law And Tchnology. [S.l.,s.n.], v.3, p.159-173, spring. 2009,

FROGNEUX, Nathalie. Du fait de la naissance à l'événement de la natalité. In: TILMANS-CABIAUX, Chantal.; RAVEZ, Laurent; DUCHÊNE, Joseph (Ed.) Éléments d'éthique périnatale: de l'obstétrique à la réanimation. Namur,Bel: Presses Universitaires de Namur, 2004. p.93-112.

FUKUYAMA, Francis. Nosso futuro pós-humano: consequências da revolução da biotecnologia. Trad. Maria Luiza X. de A. Borges. Rio de Janeiro: Rocco, 2003.

GLANNON, Walter. Extending the human life span. Journal of Medicine and Philosophy, Oxford, v.27, n.3, p.339-354, 2002.

GREISCH, Jean. L'amour du monde et le principe responsabilité. In : VACQUIN, M. (Ed.). La responsabilité: la condition de notre humanité. Paris: Editions Autrement, 1994. p.72-89.

GREY, Aubrey de. We will be able to live to 1,000. In: MOODY, Harry R. (Ed.) Aging: concepts and controversies. Thousand Oaks: Pine Forge Press, 2009, p.84-86.

HARRIS, John. Enhancing evolution: the ethical case for making better people. Princeton, New Jersey: Princeton University Press, 2007.

. Immortal ethics. Annals of the New York Academy of Sciences, New York, n.1019, p.527-534, 2004.

HÖSLE, Vittorio. Morals and politics. Notre Dame: University of Notre Dame Press, 2004. 991p.

JONAS, Hans. Acting, knowing, thinking: gleanings from hannah arendt's philosophical work. Social Research: an international quarterly, [S.l.], v.44, n.1, p.25-43, 1977.

. Contemporary problems in ethics from a jewish perspective. In: Philosophical essays: from ancient creed to technological man. Chicago: University of Chicago Press, 1980. p.168-182.

Das Prinzip Verantwortung: Versuch einer Ethik für die technologische Zivilisation 1979. Frankfurt am Main: Suhrkamp, 1984a.

The imperative of responsibility: in search of an ethics for the technological age. Trad. H. Jonas, D. Herr, Chicago: The University of Chicago Press, 1984b.

Warum wir heute eine Ethik der Selbstbeschränkung Brauchen? In: STRÖCKER, E. (Hrsg). Ethik der Wissenschaften? Philosophische Fragen. Munchen; Paderborn, W. Fink-F. Schöningh, 1984c. p.7586.

Erkenntnis und Verantwortung: Gespräch mit Ingo Hermann in der Reihe "Zeugen des Jahrhunderts". Hrsg. Von Ingo Hermann. Göttingen: Lamuv, 1991a.

. La mia controutopia. [Interview par A. Bolaffi ]. L'Unità, p.17, 5 set. 1991 b.

. O fardo e a bênção da mortalidade. Trad. Wendell Evangelista Soares Lopes. Princípios: revista de Filosofia, Natal, UFRN, v.16, n.25, p. 265-281, 2009.

KASS, Leon. L'chaim and its limits: why not immortality? In: KASS, Leon. Life, liberty and the defense of dignity: the challenge for bioethics. San Francisco, CA: Encounter Books, 2004.

KORSGAARD, Christine. Personal identity and the unity of agency: a Kantian response to parfit. Philosophy and Public Affairs, Havard, v.18, n.2, p.101-132, spring, 1989. LACEY, Hugh. O princípio de precaução e a autonomia da 
ciência. Scientiae Studia: revista Latino-Amaricano de Filosofia e História e Ciência, São Paulo, USP, v. 4, n.3, p.373-92, 2006.

MANSON, Neil, A. Formulating the precautionary principle. Environmental Ethics, v.24, n.3, p.263-274. 2002.

McCONNEL, Charles; TURNER, Leigh. Medicine, ageing and human longevity. Science \& Society, v. 6, Special Issue, p.59-62, 2005.

MORDACCI, Roberto. Intergenerational justice and lifespan extension. In: SAVULESCU, Julian,; MEULEN, Ruud ter; KAHANE, Guy. Enhancing Human Capacities. Chichester: Wiley-Blackwell, 2011. p.410-420.

NIETZSCHE, Friedrich Wilhelm. Also Sprach Zarathustra: I-IV. In: COLLI, G.; MONTINARI, M. (Ed.). Sämtliche Werke [KSA]. Munchen: Deutscher Taschenbuch Verlag; Berlin: W. de Gruyter, 1999. v.4. 420 p.

NOZICK, Robert. Philosophical explanations. Cambridge, Mass.: Belknap Press of Harvard University Press, 1981.

NORMAN, Richard. Interfering with Nature. Journal of Applied Philosophy, [S.1.], v.13, n.1, p.1-11, 1996.

OVERALL, Christine. Aging, death, and human longevity: a philosophical inquiry. Berkeley: University Presses of California, 2005

Life enhancement Technologies: the significance of social category membership. In: SAVULESCU, Julian; BOSTROM, Nick. Human enhancement. Oxford: University Press, 2009. p.327-340.

PAMPALONI, Massimo. O gesto interrompido e o grão de trigo: reflexões sobre a morte e sobre o morrer a partir de Qohelet e do mistério pascal. Perspectiva Teológica, Belo Horizonte, FAJE, v.33, n.89, p.87-104, 2001.
PARFIT, Derek. Reasons and persons. Oxford: Clarendon Press, [1984]1987. p.199-347.

PERRY, John. A dialogue on personal identity and immortality. Indianapolis: Hackett, 1978.

SHINAGAWA, Tetsuhiko. Why and how Has Hans Jonas Been "Welcomed" in Japan? A reply from Japan to LaFleur's interpretation. Journal of Philosophy of Life, Osaka, v.2, n.1, p.15-31, mar, 2012 .

SLOTERDIJK, Peter. O desprezo das massas: ensaio sobre lutas culturais na sociedade moderna. Trad. Claudia Cavalcanti. São Paulo: Estação Liberdade, 2002.

SORABJI, Richard. Self: ancient and modern insights about individuality, life, and death. Chicago: The University of Chicago Press, 2006.

SÓFOCLES. A trilogia tebana: Édipo Rei, Édipo em Colono, Antígona. Introdução e notas de Mário da Gama Kury. Rio de Janeiro: Zahar, 1990 [15a reimpressão 2011. Original em grego].

STAPLEDON, Olaf. Sirius. Übersetzung von Ilse Pauli. München, Heyne, 1984.

SUNSTEIN, Cass R. The Paralyzing Principle. Regulation, Chicago, University Press of Chicago, p.31-37, winter, 2002-2003

WALKER, Carolyn Bynum. Material continuity, personal survival, and the resurrection of the Body: a Scholastic Discussion in Its Medieval and Modern Contexts. History of Religions, New York, v.30, n.1, p.51-85, aug., 1990.

WILLIAMS, Bernard. The Makropulos case: reflections on the Tedium of immortality. In: Problems of the Self: philosophical papers 1956-1972. New York: Cambridge University Press, 1976. p.82-100. 


\section{DO WE HAVE THE DUTY TO DIE?}

\section{Wendell Evangelista Soares Lopes}

The text centers on ethical questions pertaining to death or to the prolongation of life. By attempting to offer an answer to the problem of life prolongation, or to what might be called the new scientific quest for terrain immortality, we shall reflect on today's quarrel between mortalists and immortalists. Our starting point is the acceptance of a virtual immortality as something really possible. The problem of a merely optimizing extension, i.e., of a life expectancy of 150 years for all, rises, in our view, questions which are sometimes distinct. In this sense, we wish to show that, in spite of the burden of mortality, man's mortal condition has a clear moral sense, that requires of every one a genuine duty to die - paradoxically relating to the already known rights to life and to die.

KEY-wORDS: Ethics. Life. Death. Right.

\section{AVONS-NOUS LE DEVOIR DE MOURIR?}

Wendell Evangelista Soares Lopes

L'étude se penche sur des questions éthiques relatives à la mort et à la prolongation de la vie. En essayant d'apporter une réponse au problème de la prolongation de la vie ou de ce que nous pourrions appeler une nouvelle recherche scientifique de l'immortalité terrestre, nous en viendrons à une réflexion sur la querelle actuelle entre mortalistes et immortalistes. Notre point de départ est l'acceptation d'une immortalité virtuelle considérée comme quelque chose de vraiment possible. Le problème d'une extension à peine optimisatrice, c'est-à-dire d'une espérance de vie de 150 ans pour tout le monde soulève, à notre avis, des problèmes distincts. Dans ce sens, nous avons l'intention de démontrer que malgré le poids de la mortalité, la condition mortelle de l'être humain a un sens moral clair qui exige de la part de chacun un véritable devoir de mourir - dans une relation paradoxale avec les droits déjà connus de vivre et de mourir.

MotS-CLÉs: Éthique. Vie. Mort. Droit.

Wendell Evangelista Soares Lopes - Doutorando em Filosofia pela Universidade Federal de Minas Gerais. Membro do Grupo de Pesquisa do CNPq Pensamento contemporâneo: as biotecnologias e o futuro da humanidade. Concentra suas pesquisas na área de Filosofia, com ênfase em Metafísica, Ética e Filosofia da Ciência e Filosofia da Técnica. Publicações recentes: Sobre a Fundamentação da Ética: o sentimento de responsabilidade em Hans Jonas. In: Robinson dos Santos; Jelson Oliveira; Lourenço Zancanaro. (Org.). Ética para a Civilização Tecnológica: em diálogo com Hans Jonas. 1ed. São Paulo: Centro Universitário São Camilo, 2011, p. 129-153; A renovação da teleologia em Hans Jonas: da biologia filosófica aos fundamentos da ética. Princípios (UFRN. Impresso), v. 17, p. 47-70, 2010. 
